\title{
Perspective of a new trend in organic photovoltaic: ternary blend polymer solar cells
}

\author{
Heng Lu, Xinjun $\mathrm{Xu}^{*}$ and Zhishan $\mathrm{Bo}^{*}$
}

\begin{abstract}
In the past few years, ternary polymer solar cells (PSCs) have emerged as a promising structure to simultaneously improve all solar cell parameters compared with traditional binary PSCs. The third component in ternary PSCs can play versatile functions to enhance the device performance. In this review, we summarize the design rules for fabricating high-performance ternary PSCs and introduce the recent progress in this field. In addition, the characterization methods for determining the role of the third component played in ternary PSCs are described.
\end{abstract}

Keywords: ternary blend, polymer solar cells, organic photovoltaic, bulk heterojunction, donor and acceptor

\section{INTRODUCTION}

Due to increasing consumption of unsustainable fossil fuels and the urgency of looking for the environmentally friendly and renewable energy, solar energy as the most ideal fuel becomes the hottest research area [1]. For low-cost, lightweight, and the capability to fabricate flexible large-area devices to convert sunlight to electricity, polymer solar cells (PSCs) have been hailed as one of the most promising technologies to utilize solar energy $[2,3]$.

Since the bulk heterojunction (BHJ) concept was reported in 1995 [4], two-component blend had been predominant as the active layer of PSCs. It solved a critical issue in bilayer organic photovoltaic solar cells, such as to extend interfacial area between the donor material and the acceptor material, for an efficient charge separation than Tang's bilayer-based devices [5]. Now single junction device based on binary components has reached beyond $11 \%$ power conversion efficiency (PCE) [6,7]. However, further improvement of the performance of single-junction PSCs is limited by the insufficient photon harvesting of active layers due to the relatively narrow absorption window (a few hundreds nanometer) of organic semiconductors [8].
Furthermore, another limitation recognized by Shockley and Queisser showed the trade-off between photocurrent and photovoltage in single-junction PSCs, with the efficiency of broad spectrum absorbers being reduced by the thermalization of above-bandgap excitations, named as thermalization loss [9]. Efficient strategies for further increasing the PCE of PSCs should rely on full utilization of solar light in a broad coverage and circumventing the Shockley-Queisser limit in standard single-junction devices. Compared with the single-junction PSCs, tandem solar cells cannot only improve light absorption but also reduce thermalization loss of photonic energy by stacking two or more sub-cells with complementary absorption bands, harvesting high and low energy photons in the separated sub-cells [10-13]. However, the fabrication process of tandem solar cells is complicate, leading to an increased cost and a decreased yield, which is in contrast to the attractive simplicity of the single-step solution processing for inexpensive solar cells. In recent years, ternary blend PSCs have been explored as an effective strategy to extend light absorption and improve light harvesting, resulting in higher short circuit current densities $\left(J_{\text {sc }}\right)$ and higher PCE in a single junction $[14,15]$. This strategy integrates both the enhanced photon harvesting by incorporating multiple organic materials like in tandem solar cells and simplicity of fabrication process used in single-junction solar cells.

Up to now, several excellent reviews have summarized the progress in ternary solar cells based on their unique insights $[8,15-20]$. So in this article we present a review mainly focused on the newly reported work concerning about ternary blend PSCs. Here, we confine the third component to organic semiconductors. Although other materials such as carbon nanotubes, metal nanoparticles, quantum dots, surfactants, etc. can also serve as the third com- 
ponent to enhance the device performance, they are beyond the scope of this review. As the third component usually played versatile functions in the active layer with different donor:acceptor (D:A) systems, we also briefly introduce the methods used to distinguish which kind of mechanism is responsible for improving the device performance in ternary PSCs. In the first part, we will discuss the design rules of ternary blend PSCs. Then, we present and discuss the main types of ternary blend PSCs reported in recent years. After that, the characterization methods for determining the role of the third component played in PSCs are described. Finally, the possible research direction in the near future has been discussed.

\section{DESIGN RULES OF TERNARY BLEND PSCs}

The third component plays a very important role in achieving high-efficiency ternary blend PSCs. In this part, we will discuss the fundamental design rules for ternary blend PSCs in terms of light absorption, morphology, charge transfer and charge transport.

\section{To extend or enhance the absorption spectra of active layer} In most systems of PSCs, the vast majority of the photocurrent is attributed to the absorption of the donor materials. When another electron donor or acceptor material was added in a traditional binary system to form a typical ternary blend PSCs, this third component was often chosen to have complementary absorption with respect to that of the reference device. As a result, light absorption can be extended for better matching with the solar spectrum to increase the short circuit density. For example, Koppe et al. [21] extended the spectroscopic response of a poly(3-hexylthiophene)/[6,6]-phenyl- $\mathrm{C}_{61}$-butyric acid methyl ester (P3HT/PCBM)-based BHJ solar cell into the near infrared region (NIR) of the spectrum by incorporating the low bandgap polymer poly[2,6-(4,4-bis-(2-ethylhexyl)-4H-cyclopenta[2,1-b;3,4-b']-dithiophene)-alt-4,7-(2,1,3-benzothiadiazole)] [PCPDTBT] into the blend. The PCE can be improved from $2.5 \%$ (the binary system) to $2.8 \%$ (the ternary system). Before 2012, most of the researchers work on the ternary solar cells based on $\mathrm{P} 3 \mathrm{HT}$ as the dominating donor. Although the device efficiency could be enhanced in ternary PSCs based on P3HT with various dopants, the overall performance of the corresponding ternary devices is still limited by the relatively poor performance of the binary (e.g., P3HT:PCBM) reference cells. It should also be noted that the dopants best suited to a P3HT system cannot be directly applied to high-performance donor-acceptor (D-A) low-bandgap copolymer systems due to the dramatically different optoelectronic properties of $\mathrm{P} 3 \mathrm{HT}$ and D-A low-bandgap polymers. To surmount this problem, other polymer systems have been developed. Yang et al. [22] reported ternary PSCs with a parallel-like BHJ by using two groups of polymers as the donors: (1) poly(benzodithiophene-dithienylbenzotriazole) and poly(benzodithiophene-dithienylbenzothiadiazole) (DTBT), (2) poly(benzodithiophene-dithienyldifluorobenzothiadiazole) (DTffBT) and poly(benzodithiophene-dithienylthiadiazolopyridine) (DTPyT). In these ternary devices, free charge carriers travel through their corresponding donor-polymer-linked channels and fullerene-enriched domain to the electrodes, equivalent to a parallel-like connection (Fig. 1a). The absorption spectra and external quantum efficiency (EQE) curves of the ternary devices based on TAZ/DTBT and DTffBT/DTPyT show extended absorption region relative to the "subcell" with wide-bandgap polymer (TAZ or DTffBT) and enhanced absorption intensity relative to the "subcell" with low-bandgap polymer (DTBT or DTPyT), respectively (Figs $1 \mathrm{~b}$ and $c)$. The short-circuit current $\left(J_{s c}\right)$ of the ternary solar cell is nearly identical to the sum of those of the individual "subcells", while the open-circuit voltage $\left(V_{\text {oc }}\right)$ is between those of the "subcells". Nearly $30 \%$ enhancement in overall efficiency has been achieved in comparison with the binary single-junction devices. In the case of such a parallel-like connection, the two polymer donors with different band gaps can be employed at any composition, regardless of their highest occupied molecular orbital (HOMO) or lowest unoccupied molecular orbital (LUMO) levels. Although broadening the absorption bandwidth of PSCs by employing multiple absorber donors in the $\mathrm{BHJ}$ active layer is an attractive means of surmounting the narrow absorption of organic semiconductors, only limited success has been demonstrated. To find out the reason, Yang's group [23] fabricated several dual-donor and multi-donor BHJ PSCs based on a pool of materials with different absorption ranges and preferred molecular structures. The corresponding device performance was investigated. Their study shows that compatible polymer donors can coexist harmoniously, but the mixing of incompatible polymers can lead to severe molecular disorder and limit device performance.

\section{Form a better morphology}

The active layer of binary blend PSCs based on the BHJ concept offers the possibility of forming a bi-continuous interpenetrating network of individual donor material and 

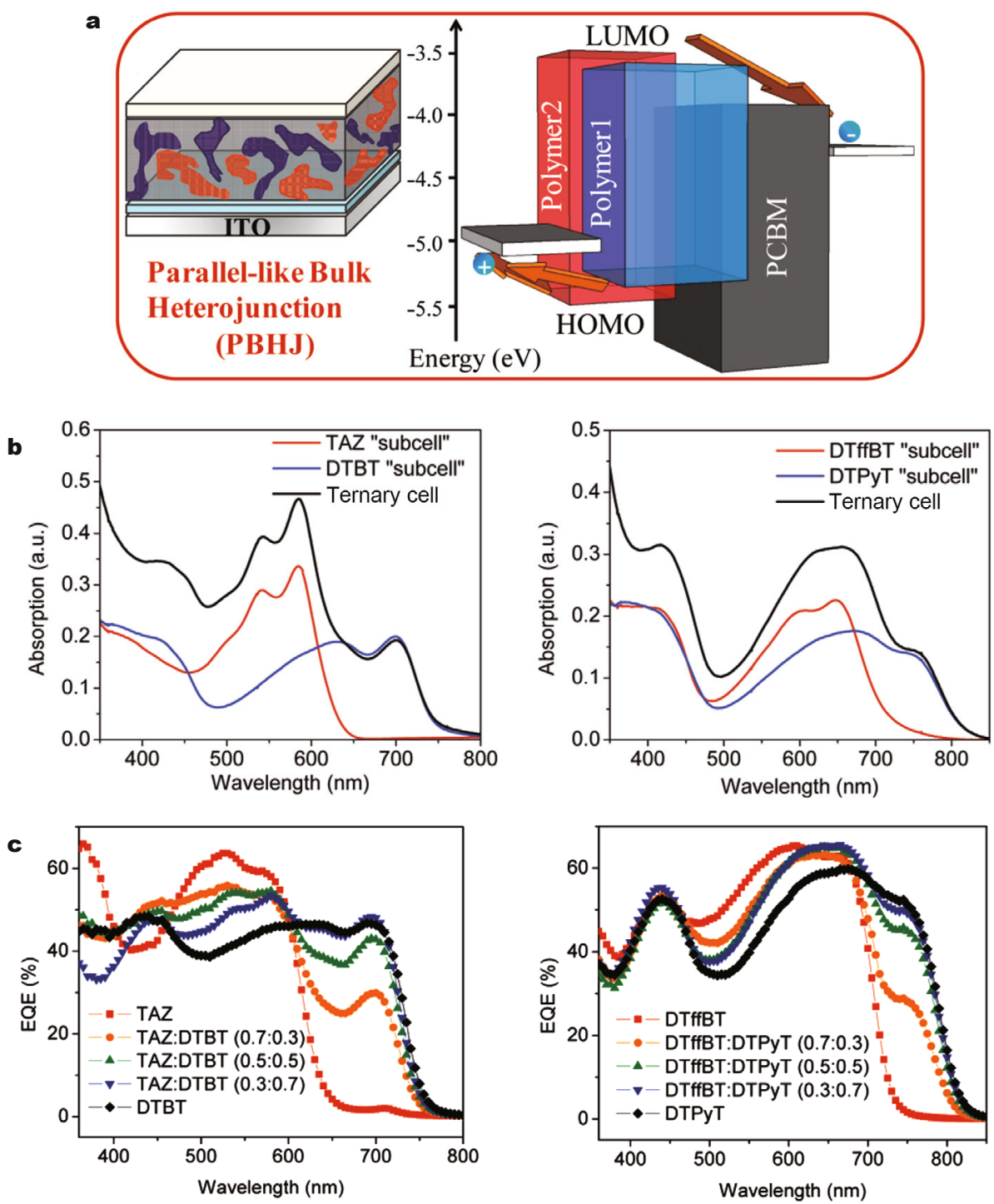

Figure 1 (a) Schematic structure and energy diagram of the parallel-like BHJ ternary PSC. (b) Absorption spectra of the parallel-like BHJ devices and their "subcells" based on TAZ/DTBT and DTffBT/DTPyT. (c) EQEs of the PBHJ devices and their "subcells" based on TAZ/DTBT and DTffBT/DTPyT. Reprinted with permission from Ref. [22]. Copyright 2012, American Chemical Society.

acceptor material. However, in the most widely used binary blend systems, the electron acceptor (PCBM) tends to aggregate into big clusters, which destroys the morphology of the active layer and reduces the PCE drastically [24,25]. The added third component can be designed to achieve better morphology compared to the reference devices. The third component can restrain the aggregation of PCBM to achieve suitable phase separation via some special intermolecular interactions. For example, Campoy-Quiles et al. [26] reported that small amounts of amorphous regiorandom $\mathrm{P} 3 \mathrm{HT}$ could be used to create a dilute matrix to reduce phase separations in regioregular P3HT (RR-P3HT):PCBM devices (see Fig. 2). A better morphol- ogy can be achieved via reduced micrometer-sized PCBM domains and RR-P3HT crystallite sizes.

In contrast to RR-P3HT, for D-A polymers without a very good crystallinity, the third component which can tune the morphology of polymer donors to form more ordered domains will be beneficial to increase the device performance. Wei's group [27] reported a ternary PSC with a D-A-type polymer containing benzo[1,2-b:4,5-b'] dithiophene and thieno[3,4-c]pyrrole-4,6-dione groups (named as PBDTTPD-HT) and a high-crystallinity small molecule (BDT-3T-CNCOO). For the binary systems, the crystalline domain size of BDT-3T-CNCOO is ca. 22.5 $\mathrm{nm}$, while it is only $2.62 \mathrm{~nm}$ for PBDTTPD-HT. However, 
a

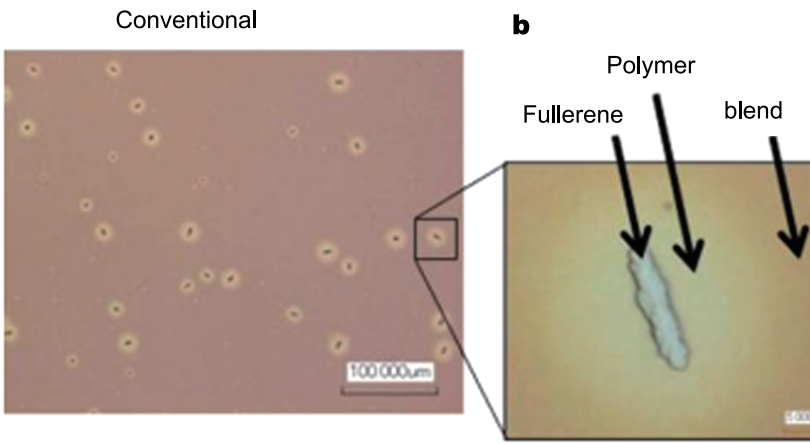

d

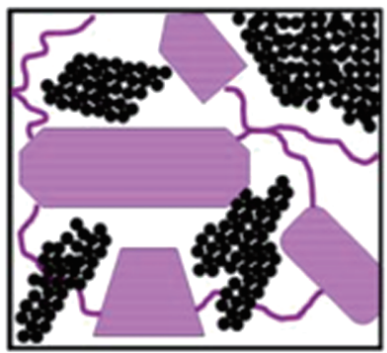

e

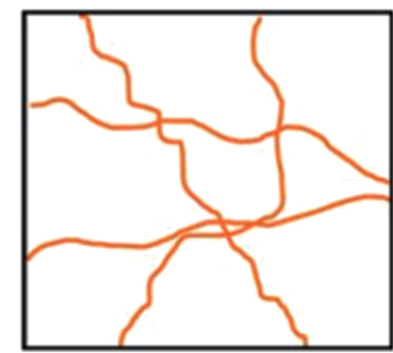

c

Ternary blend

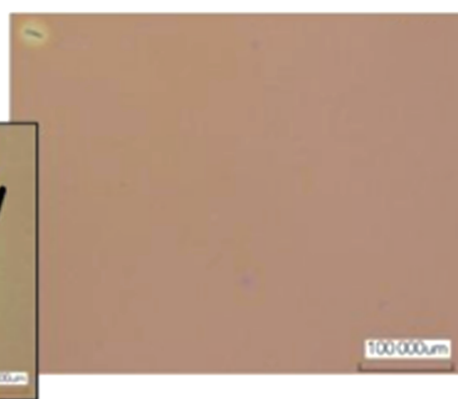

f

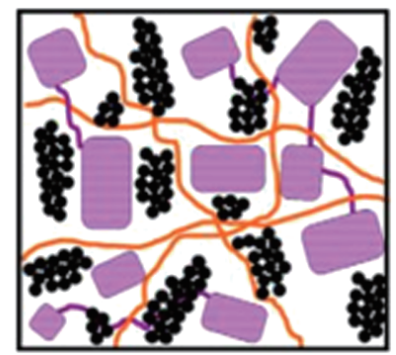

Figure 2 Comparison of the morphology of the binary (conventional) blend and the ternary systems. (a-c) UV laser microscope images of annealed blends with PCBM:regular P3HT:random P3HT concentrations of (a) 1:1:0; (b) 1:1:0 (zoom-in detail); and (c) 4:3:1; (d-f) schematics of (d) a binary PCBM:regular P3HT blend; (e) dilute random polymer matrix; and (f) ternary system comprising a dilute random P3HT matrix filled with crystallites of PCBM and regular P3HT. Reprinted with permission from Ref. [26]. Copyright 2009, Elsevier.

in the ternary systems, increasing weight ratios of BDT-3TCNCOO strengthens the diffraction peaks, which indicates the crystallinities of donor materials are adjusted gradually. Therefore, adding small molecular donor with a high crystallinity into polymer-based active layer is a useful method for promoting the crystallization of the polymers as well as tuning crystalline domain sizes of donor materials (Fig. 3).

Besides small molecules, polymers are also found to be able to improve the nanoscale film morphology. Yu's group [28] has successfully developed a ternary PSC system with improved efficiency by incorporating poly-3-oxothieno[3, 4-d]isothiazole-1, 1-dioxide/benzodithiophene (PID2) into a poly\{4, 8-bis[(2-ethylhexyl)oxy]benzo[1, 2-b:4, 5-b']-dithiophene-2, 6-diyl-alt-3-fluoro-2-[(2-ethylhexyl)carbonyl] thieno[3, 4-b] thiophene-4, 6-diyl\} (PTB7): $[6,6]$-phenyl $\mathrm{C} 71$ butyric acid methyl ester $\left(\mathrm{PC}_{71} \mathrm{BM}\right)$ host blend. A ternary blend solar cell containing $10 \mathrm{wt} . \%$ PID2 demonstrated the highest PCE at $8.22 \%$. It was found that the use of PID2 at low contents led to favorable fibrillar structures and smaller domain sizes than the control device. These smaller domains would increase the area of the interfaces between polymer donors and fullerene acceptors, thus facilitating exciton dissociation and leading to improved device performance.

\section{More efficient charge transfer and charge transport}

Because the charge separation occurs at the donor/acceptor interface in BHJ PSCs, the offsets of the HOMOs and LUMOs of the donor and the acceptor should be suitable. Too small offsets can hardly provide enough driving force for efficient charge transfer [29,30], while too large offsets will lead to much unnecessary energy loss for exciton dissociation, resulting in a small $V_{\text {oc }}$. The third component as a role of an electron/hole-cascade for more efficient charge transfer has been adopted in most of ternary blend PSCs. The cascade like energy levels (shown in Fig. 4) of ternary blend PSCs can facilitate charge transfer at the D/A interface owing to the bridging effect to reduce the energy loss [31,32]. For example, Huang et al. [33] reported that by incorporating a small molecule donor $7,7^{\prime}-\left\{5,5^{\prime}-[10,12\right.$ bis(4-tert-butylphenyl)dibenzo[f,h]thieno[3,4-b]quinoxaline-2,7-diyl]bis(thiophene-5,2-diyl)\}bis(9,9-dihexyl- $N, N$ diphenyl-9H-fluoren-2-amine) (TQTFA) into PSCs based on P3HT:PC ${ }_{71} \mathrm{BM}$, a cascade energy level structure can be formed, leading to a higher short-circuit current and open-circuit voltage.

In PSCs, after charge separation at the D/A interface, charge carriers are transported along their individual pathways and collected at the electrode [34]. Therefore, charge 
a

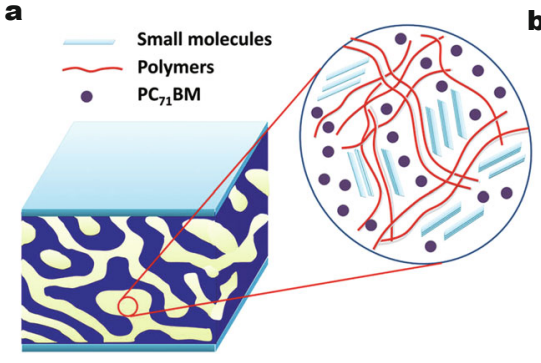

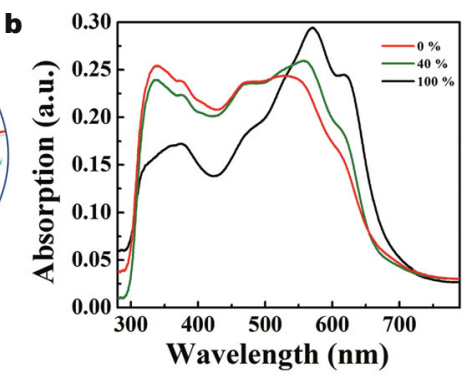

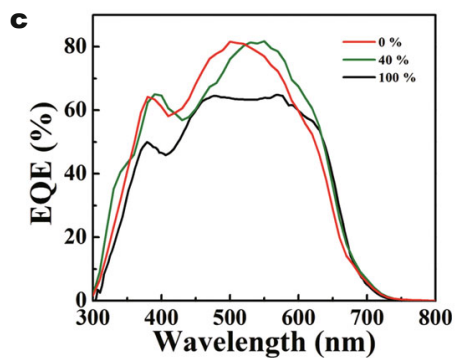

d

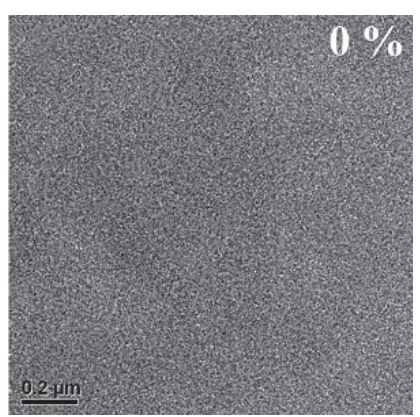

e

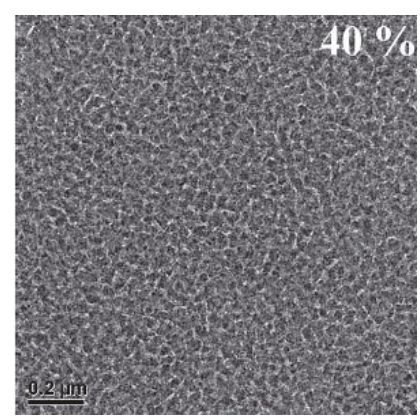

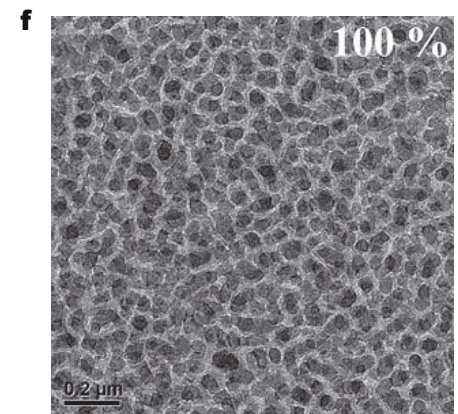

Figure 3 (a)Illustration of the active layer of ternary solar cells, in which the addition of small molecules increased the crystallinity of the donor phase. (b) UV-vis absorption spectra and (c) EQE curves of the active layer with different BDT-3T-CNCOO ratios. (d-f) Morphologies of the blends with different BDT-3T-CNCOO ratios characterized by TEM. Reprinted with permission from Ref. [27]. Copyright 2015, Wiley-VCH.

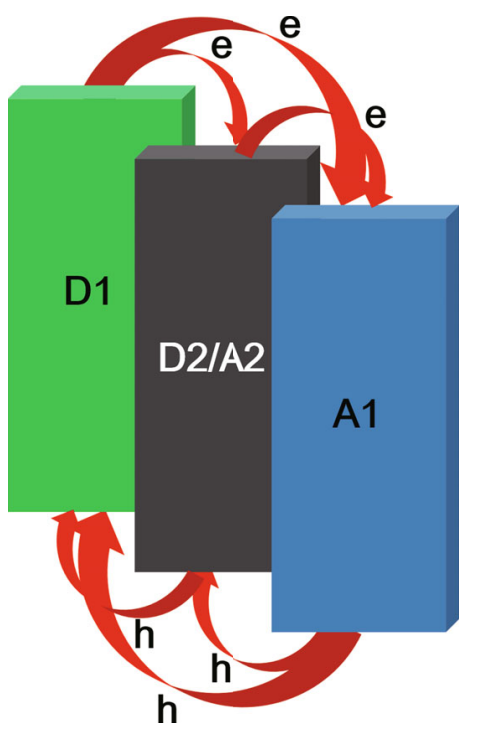

Figure 4 The cascade like energy levels of ternary blend PSCs.

transport is very important for PSCs. One limitation for many PSCs is the low hole mobilities of polymer donors [35], which prohibit the further improvement of the device performance. A reasonable approach to overcome this limitation is to introduce high-mobility materials as additives in the active layers. Bearing this strategy in mind, Liu et al. [36] investigated the influence of two high hole-mobility polymer additives on the device performance. One of the polymers contains alkyldiketopyrrolopyrrole and dithienylthieno[3, 2-b] thiophene units (DPP-DTT) and the other polymer is poly[2, 5-bis(alkyl)pyrrolo[3, 4-c]pyrrole-1, 4(2H, 5H)-dione-alt-5, 5'-di(thiophene-2-yl)-2, 2'-(E)-2-(2-(thiophen-2-yl)vinyl)thiophene] (PDVT-10), both of which have hole mobilities $\left(\sim 10 \mathrm{~cm}^{2} \mathrm{~V}^{-1} \mathrm{~s}^{-1}\right)$ about four orders of magnitude higher than those of conventional PSCs $[37,38]$. When adding $1 \mathrm{wt} . \%$ DPP-DTT to PTB7:PCBM based devices, significant improvement of PCE $(8.33 \% \pm 0.13 \%)$ can be achieved relative to the binary control device (PCE: 7.58\%), which resulted from the increases in $J_{\mathrm{sc}}$ and $V_{\mathrm{oc}}$. Similarly, when adding 0.5 wt.\% PDVT-10 to PBDTTT-EFT:PC 71 BM based devices, the average PCE can also be enhanced from $8.75 \%$ to $10.08 \%$. However, when adding DPP-DTT to the PBDTTT-EFT:PC ${ }_{71} \mathrm{BM}$ based devices, PCE of the ternary devices decreases with increasing the DPP-DTT weight percentage because a cascade band structure is absent in this ternary system. The results show that to effectively increase the hole mobilities of the devices, the additive should have a similar HOMO level to that of the donor material. Even several tens of millivolts may lead to a completely different effect. In addition, the additive should form a cascade band structure in the PSCs to avoid the 
trapping of carriers in the additive.

\section{MAIN TYPES OF TERNARY BLEND PSCS}

In this part, we focus our discussion on the recent development of ternary blend PSCs in the past few years. The main three types of ternary blend PSC include two donors/one acceptor, one polymer donor/two acceptors and polymer donor/bipolar compound/acceptor.

\section{Two donors and one acceptor $\left(\mathrm{D}_{1}-\mathrm{D}_{2}-\mathrm{A}\right)$ system}

Wide band gap and low band gap polymer donor materials are commonly chosen to broaden the absorption spectra for manufacturing ternary blend PSCs. Some representative light-absorbing polymers were summarized in Chart 1. Bo's group [39] developed a ternary blend system that contained two conjugated polymers HD-PDFC-DTBT (simply abbreviated as HD) and DT-PDPPTPT (simply abbreviated as DPP) with complementary absorption feature to expand the absorption profile of the active layer. More importantly, the DT-PDPPTPT component can form fibrous nanostructures for hole transport. The device structure and absorption spectra of polymers HD and DPP are shown in Fig. 5. Such ternary PSCs show a PCE of $6.71 \%$, surpassing the corresponding binary PSCs. With the increase of the weight ratio of $\mathrm{HD}$ in the ternary blend, $V_{\mathrm{oc}}$ increased gradually from 0.79 to $0.97 \mathrm{~V}$. For $\mathrm{BHJ}$ polymer solar cells, an empirical relation of $q V_{\mathrm{oc}} \approx E_{\mathrm{CT}}-0.5 \mathrm{eV}$ ( $q$ is the elementary charge and $E_{\mathrm{CT}}$ is the energy of charge transfer (CT) state) has been used to estimate the $V_{\text {oc }}$ under one sun illumination intensity at room temperature. The CT-state energy shifts with the composition of the blend, resulting in the changing of $V_{\mathrm{oc}}[40]$.

Yu's group [41] demonstrated an efficient ternary blend PSC with a PCE of 9.2\% based on poly[4, 8-bis(5-(2-ethylhexyl)thiophen-2-yl)benzo[1, 2-b:4, 5-b']dithiophene-co-3-fluorothieno[3, 4-b]thiophene-2-carboxylate] (PTB7-Th): PID2:PC ${ }_{71} \mathrm{BM}$ with 20 wt.\% PID2 loading. They show that the third component can reduce the surface

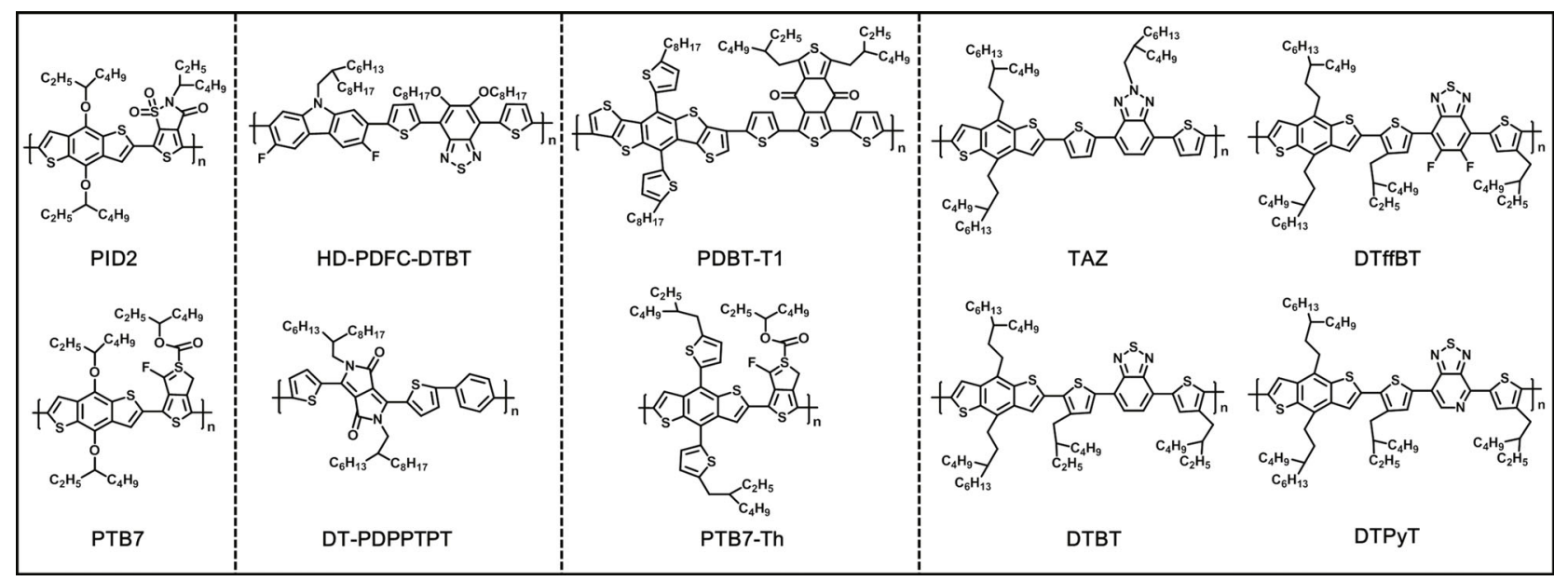

Chart 1 The molecular structures of the representative light-absorbing polymers used in ternary blend PSCs.
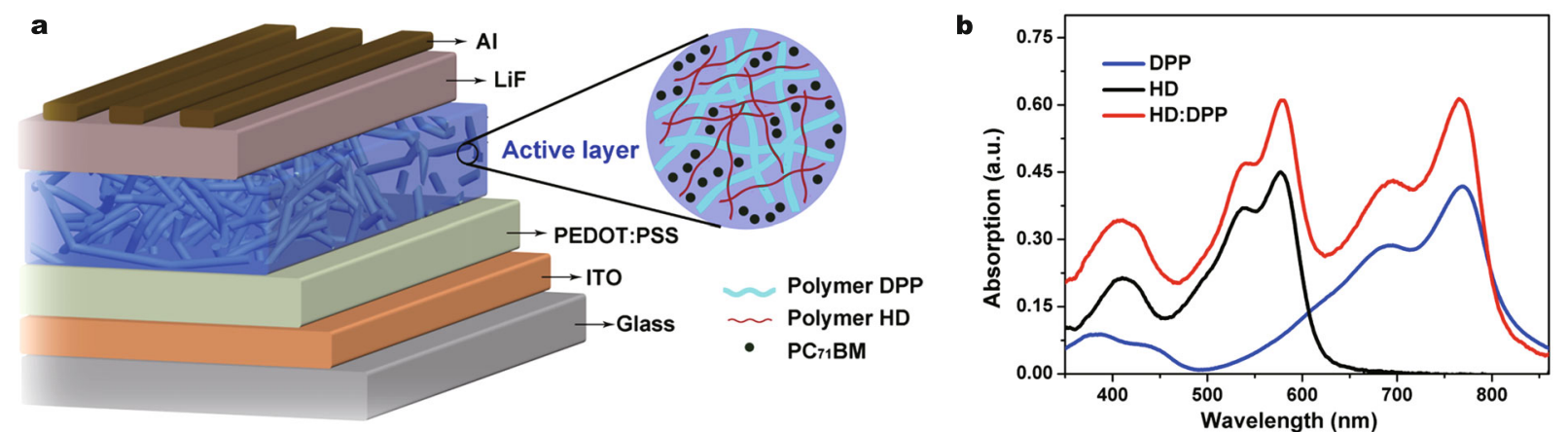

Figure 5 (a) Device structures of ternary blend PSCs; (b) UV-vis absorption spectra of HD, DPP, and the blend of HD:DPP (1:1, w/w) films. Reprinted with permission from Ref. [39], Copyright 2015, Wiley-VCH. 
trap densities in the ternary blend. The improved performance results from synergistic effects of enlarged open circuit voltage, suppressed trap-assisted recombination, enhanced light absorption, increased hole extraction, efficient energy transfer and better morphology. Sun's group [42] demonstrated a high-performance ternary solar cell by using a well-established wide-bandgap polymer, PDBT-T1, as the additional donor, which shows complementary spectra with PTB7-Th. In addition, the polymer crystallinity in the blend can be improved through incorporation of the high-crystalline PDBT-T1 donor. As a result, a high PCE of $10.2 \%$ was obtained for ternary solar cells.

Conjugated polymers normally have a good compatibility with fullerene acceptors. However, the crystallinity of conjugated polymers is usually low, being insufficient to obtain optimal morphology. Therefore, ternary PSCs fabricated by using two miscible donors-one is a high-performance polymer and the other is a high-crystalline small molecule-may form alloy and increase the crystallinity simultaneously, which will potentially yield high efficiency ternary PSC. Wei's group [14] incorporated a high crystallinity small molecule 7, 7-(4, 4-bis(2-ethylhexyl)-4H-silolo[3, 2-b:4,5-b']dithiophene-2, 6-diyl)bis(6-fluoro-4-(5'-hexyl-[2, 2'-bithiophen]-5yl)benzo- $[c][1,2,5]$ thiadiazole) ( $p$-DTS(FBTTH2) $)_{2}$ ) into a host binary blend of PTB7-Th:PC ${ }_{71} \mathrm{BM}$. Both the crystallinity and the face-on preferential orientation with respect to the substrate are enhanced when the small molecule is added, thus resulting in an average PCE of $10.5 \%$ by adding a $15 \%$ weight ratio of $p$-DTS(FBTTH2) 2 which is much higher than the binary system based on PTB7-Th:PC ${ }_{71}$ BM (an average PCE of 9.2\%). Similarly, Kan et al. [43] reported that a small molecular compound 5,5'-bis(3,5-di-tert-butyl-4-oxo-2,5-cycloexadien-1-ylidene)-5,5'-dihydro-2,2'-bithiophene (QBT) can serve as a nucleation agent to induce striking modifications in the P3HT lamellar stacking direction, forming both densely packed and loosely packed P3HT chains. An improvement in the charge transport properties is verified that links directly to the appearance of the densely packed rr-P3HT polymorph, when QBT loadings of 0.3-0.6 wt.\% content are used.

As the short-circuit currents of the PTB7-based solar cell are still not excellent due to insufficient light absorption in the near-infrared region, Xiao et al. [44] utilized a zinc porphyrin derivative (DPPEZnP-O), which has a wide and strong absorption in the near-infrared region, to act as the third component in PSCs. Compared to the PTB7:PC 71 BM binary solar cells, which show a PCE of $7.47 \%$, the ternary devices with 20 wt.\% DPPEZnP-O incorporation exhibit an improved PCE of $8.39 \%$ with largely improved $J_{\text {sc. }}$.

Cha et al. [31] developed a naphthalene derivative polymer donor material, PBTADN, and the acceptor material, $\mathrm{PC}_{71} \mathrm{BM}$, were blended with either of two different anthracene-based star-shaped conjugated small molecules, HBantHBT and BantHBT, which provided intermediate energy levels to produce a ternary cascade energy structure. The cascade structure effects of the star-shaped conjugated small molecules were examined in a P3HT:PC ${ }_{61} \mathrm{BM}$ blend system.

Although ternary blend PSCs based on two donors (wide- and low-bandgap polymers or one polymer donor and a small molecular donor) and fullerene derivatives have been demonstrated to achieve a higher PCE than the original binary ones, this concept has rarely been applied to enhance the efficiency of polymer/polymer BHJs (where the acceptor is a n-type polymer), because such ternary blend systems require not only complementary absorption bands but also sufficient free carrier generation and effective charge transport properties of both constituent binary blends. Benten et al. [45] reported high-performance ternary blend all-polymer solar cells with complementary absorption bands from visible to near-infrared wavelengths. By introducing poly[ $N$-9'-heptadecanyl-2,7-carbazole-alt-5,5-(4',7'-di-2-thienyl-2',1',3'-benzothiadiazole)] (PCDTBT) as a second donor into the highly efficient low-bandgap PBDTTT-EF-T (also called as PTB7-Th)/ poly $\left\{\left[N, N^{\prime}\right.\right.$-bis(2-octyldodecyl)-naphthalene-1,4,5,8-bis(dicarboximide)-2,6-diyl]-alt-5,5'-(2,2'bithiophene) (N2200) blend, they found that PCDTBT can contribute to efficient photocurrent generation in the ternary blends. When containing $10 \mathrm{wt} . \%$ PCDTBT, the ternary blend all-polymer $\mathrm{BHJ}$ solar cells show that the EQEs at visible wavelengths are successfully increased up to $65 \%-70 \%$, and a PCE as high as $6.65 \%$ is obtained.

\section{One polymer donor and two acceptors $\left(D-A_{1}-A_{2}\right)$ system}

Differing from the aforementioned style of ternary PSCs, in this part we focus on the two acceptors system. Chemical structures of varied acceptors and common donors are shown in Chart 2. Ko et al. [46] reported a new approach to realize efficient ternary PSCs via the incorporation of both $\mathrm{PC}_{61} \mathrm{BM}$ and $\mathrm{PC}_{71} \mathrm{BM}$ as mixed acceptors and the conjugated polymer PTBT as a donor. This report shows that the ternary blend of PTBT:PC ${ }_{61} B M: \mathrm{PC}_{71} \mathrm{BM}$ results in a remarkable improvement in the PCE compared to binary mixtures of the components via enhanced light absorption by $\mathrm{PC}_{71} \mathrm{BM}$ and balanced charge transport by $\mathrm{PC}_{61} \mathrm{BM}$. 


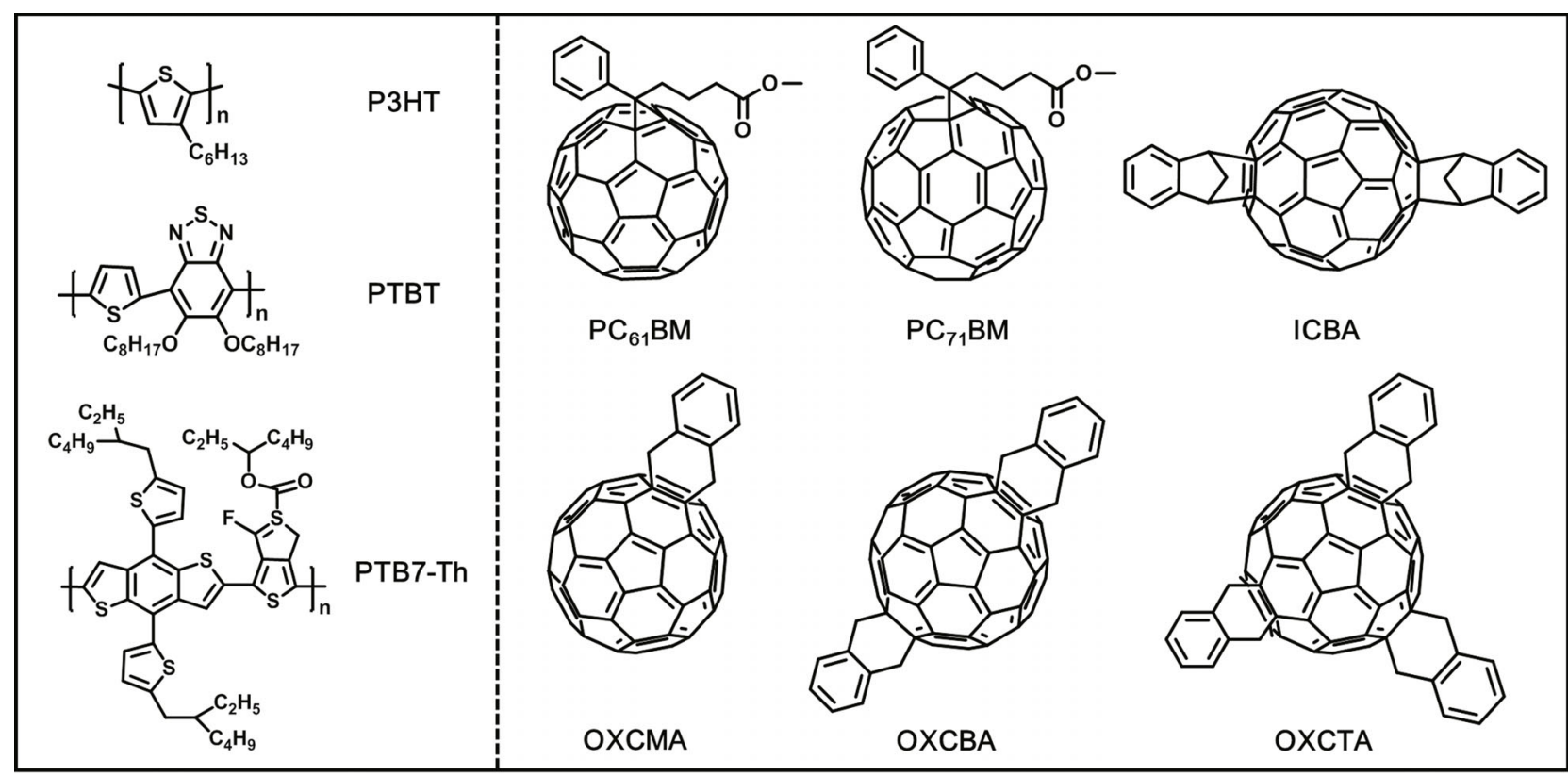

Chart 2 Chemical structures of varied acceptors and common donors.

Zhan's group [47] used indene-C60 bisadduct (ICBA) as an electron-cascade acceptor material in PTB7:PC ${ }_{71} \mathrm{BM}$ blend to fabricate ternary blend PSCs. Due to the higher LUMO energy level of ICBA relative to $\mathrm{PC}_{71} \mathrm{BM}$, the open circuit voltage increases with the addition of ICBA. ICBA plays a bridging role between $\mathrm{PTB} 7$ and $\mathrm{PC}_{71} \mathrm{BM}$, thus providing more routes for charge transfer at the donor/acceptor (D/A) interface. When the ICBA content is much smaller than the $\mathrm{PC}_{71} \mathrm{BM}$ content, the morphology of the ternary blend active layer is similar to that of the PTB7:PC ${ }_{71} \mathrm{BM}$ blend, which guarantees suitable phase separation and efficient charge transport. Ternary blend devices with $15 \%$ ICBA content exhibit an average PCE of $8.13 \%$, higher than that $(7.23 \%)$ of the PTB7:PC ${ }_{71}$ BM binary blend. Kang et al. [32] used fullerene tris-adducts to fully exploit the merit of their high LUMO level. The compound OXCTA was used as a ternary acceptor in the model system of P3HT as the electron donor and fullerene monoadduct as the acceptor. They found that OXCTA can generate a synergistic bridging effect between P3HT and the fullerene monoadduct, leading to a simultaneous enhancement in both $V_{\text {oc }}$ and short-circuit current $\left(J_{\text {sc }}\right)$.

\section{One polymer donor, one acceptor and a bipolar component} (D-A-B) system

Commonly, the third component in a ternary PSC is either a donor (p-type semiconductor) or an acceptor (n-type semiconductor). So only one kind of charge carrier it can prefer to transport. Recently, Chen's group
[48] reported a new diketopyrrolopyrrole small molecule $\left(\mathrm{F}(\mathrm{DPP})_{2} \mathrm{~B}_{2}\right)$ with bipolar charge-transporting property. When it is used as either an acceptor blended with P3HT or a donor blended with PCBM, the resulting organic solar cells demonstrate good PCEs over 3\%, which shows that $\left(\mathrm{F}(\mathrm{DPP})_{2} \mathrm{~B}_{2}\right)$ has a bipolar charge-transporting property. This compound shows intense absorption in the range of 550-700 nm which is complement well with that of P3HT and exhibits suitable HOMO and LUMO energy levels matching perfectly those of PCBM and P3HT to form a cascade structure. A best PCE of $3.92 \%$ is obtained in the ternary P3HT:F(DPP $)_{2} \mathrm{~B}_{2}: \mathrm{PC}_{61} \mathrm{BM}$ PSCs with a 5 wt.\% $\mathrm{F}(\mathrm{DPP})_{2} \mathrm{~B}_{2}$ loading in acceptor, corresponding to about 23\% improvement compared with that of $3.18 \%$ PCE for P3HT:PC ${ }_{61} \mathrm{BM}$ based cell [49]. The performance improvement of the ternary PSCs can be attributed to the simultaneous improvement of the light harvesting, exciton dissociation, and charge carrier transport by the introduction of the third bipolar component.

\section{CHARACTERIZATION METHODS}

As mentioned above, the third component in ternary PSCs may play versatile functions including complementary light harvesting, facilitating exciton dissociation, enhanced charge transport, and optimized morphology to improve the device performance. To distinguish which roles are dominant, various characterization methods are needed. In this part, we will briefly introduce these characterization methods reported in the literature. 


\section{Absorption and EQE characterization}

The effect of the third component to extend the absorption of solar energy in ternary PSCs can be directly verified by the absorption spectrum measurement. In addition, this extended absorption can also be reflected in the EQE curves. Moreover, EQE measurements can be utilized to probe the D:A interfacial energetics through the charge-transfer state (an intermolecular state formed between the donor and acceptor) absorbance. The CT region of the EQE spectra can be fitted with Equation (1):

$$
\mathrm{EQE} \propto \frac{f}{E \sqrt{4 \pi \lambda k T}} \exp \left(\frac{-\left(E_{\mathrm{CT}}+\lambda-E\right)^{2}}{4 \lambda k T}\right),
$$

where $E$ is the photon energy, $k$ is the Boltzmann constant, $f$ is a term that accounts for the internal quantum efficiency, number of CT states, and electronic coupling, $E_{\mathrm{CT}}$ is an effective energy of the CT state, and $\lambda$ is related to the width of the CT absorbance band which results from internal reorganization, environmental reorganization, and energetic disorder [50,51]. A narrower CT band (a lower $\lambda$ value) means a more specific and consistent arrangement between donor and acceptor, thus the energetic disorder is reduced, while a broader distribution of D:A arrangements would increase the energetic distribution of CT states and increase $\lambda$ (Fig. 6) [52].

\section{Energy transfer characterization}

The third component in ternary PSCs can act as either an "energy donor" or an "energy acceptor". When the third component only acts as the "energy donor", all holes are generated in the dominating donor and the third component works just as a sunlight absorber. The additional absorbers can harvest more photons and transfer these extra photon energies to the other components. When the third component serves as an "energy acceptor", it should make close contact with a donor or an acceptor to dissociate excitons generated in it. Photoluminescence (PL) spectrum is a convenient tool to probe energy transfer. For example, in the $\mathrm{D}_{1}: \mathrm{D}_{2}$ :A ternary system, after introducing the third component $\left(\mathrm{D}_{2}\right.$, which exhibits an NIR absorption and has a lower bandgap than $D_{1}$ ), energy transfer between $D_{1}$ and $\mathrm{D}_{2}$ would manifest itself in two observations: an increased photoluminescence of $\mathrm{D}_{2}$, concomitant with a quenching of PL signal of $\mathrm{D}_{1}$ in the visible spectroscopic range.

\section{Charge transfer and separation characterization}

The charge transfer in ternary blend films is a competing process compared with the energy transfer among the components. PL spectrum can also be utilized to monitor this

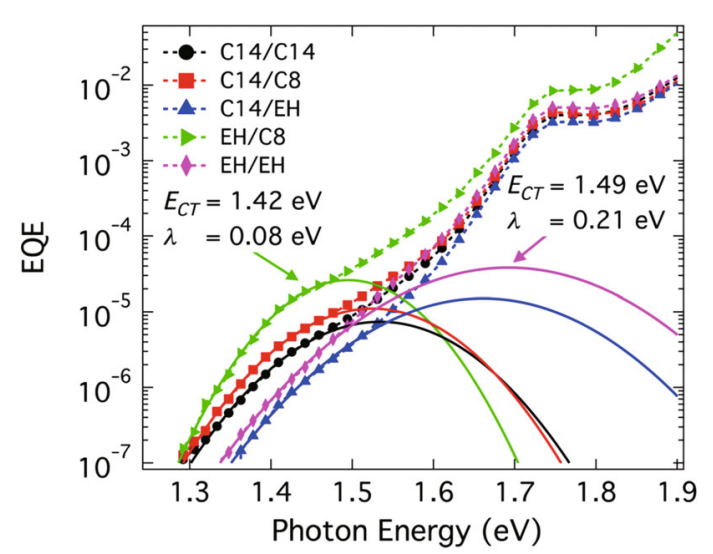

Figure 6 EQE spectra of the CT region, with fits to Equation (1) indicated with solid lines. Reprinted with permission from Ref. [51]. Copyright 2014, American Chemical Society.

mechanism. For example, in the PTB7:PID2:PC ${ }_{71} \mathrm{BM}$ ternary PSCs, the photoluminescence of PID2 was completely quenched while the photoluminescence of PTB7 remained almost the same in the PTB7:PID2 blends (both 0.9:0.1 and 0.7:0.3) (Fig. 7). The results show that it is not the energy transfer between PID2 and PTB7 but the photoinduced electron transfer from PTB7 to PID2 (hole transfer from PID2 to PTB7) that exists in the blended film [28].

a
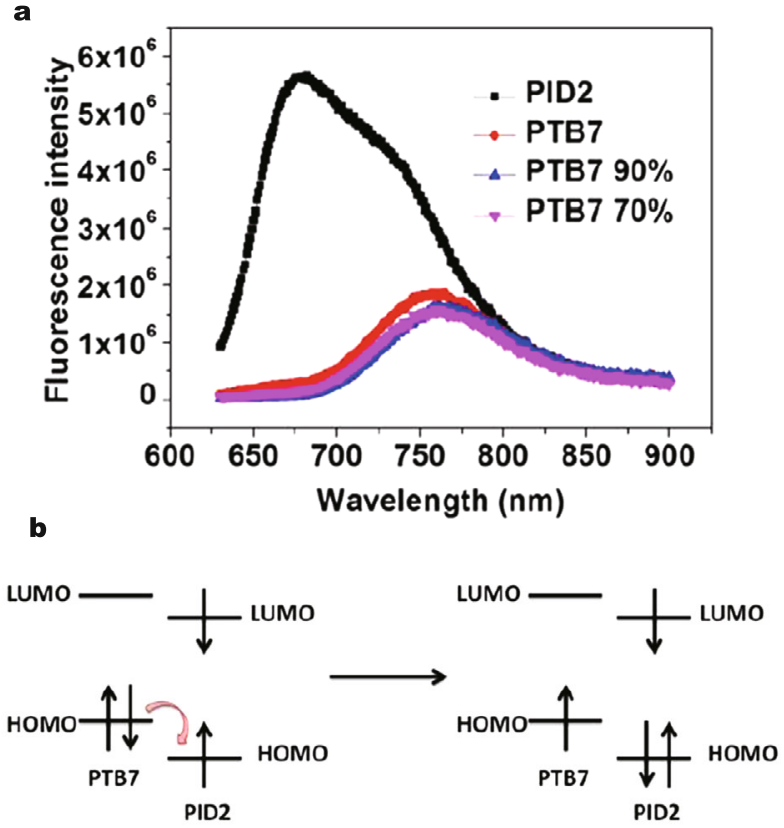

Figure 7 (a) Photoluminescence spectra of PID2, PTB7, PTB7:PID2 $(0.9: 0.1,0.7: 0.3)$ excited at $610 \mathrm{~nm}$. (b) Schematic of photoinduced charge transfer from PTB7 to PID2. Reprinted with permission from Ref. [28]. Copyright 2014, Macmillan Publishers Limited. 
Steady state photoinduced absorption (PIA) measurements can be also utilized to check whether or not charge transfer processes occur between the components in ternary PSCs. For example, in the P3HT:PCPDTBT:PCBM blended film, two different pump energies were used for the selective excitation of PCPDTBT and P3HT. PCPDTBT absorbs strongly at a pump energy of $1.59 \mathrm{eV}$, while the $\mathrm{P} 3 \mathrm{HT}$ absorption at this wavelength is negligible. At 2.33 $\mathrm{eV}$, both compounds absorb. As shown in Fig. 8, excitation of a pristine PCPDTBT film at $2.33 \mathrm{eV}$ generates a radical cation, whose absorption band peaks at $0.96 \mathrm{eV}$. Excitation of the P3HT:PCPDTBT (0.8:0.2) blend at the same energy $(2.33 \mathrm{eV})$ increases the signal intensity (at $0.96 \mathrm{eV})$ by a factor of 6 to 8. This enhancement of the PCPDTBT polaron signal indicates photoinduced electron transfer from P3HT to PCPDTBT [21].

The effect of the third component on the exciton dissociation process in ternary PSCs can be determined by the variation of saturation photocurrent density $\left(J_{\text {sat }}\right)$ and charge dissociation probabilities $P(\mathrm{E}, \mathrm{T}), P(\mathrm{E}, \mathrm{T})$ is calculated by normalizing photocurrent density $\left(J_{\mathrm{ph}}\right)$ with $J_{\text {sat }}$ $\left(J_{\mathrm{ph}} / J_{\mathrm{sat}}\right)[53] . J_{\mathrm{ph}}=J_{\mathrm{L}}-J_{\mathrm{D}}$, where $J_{\mathrm{L}}$ and $J_{\mathrm{D}}$ are the current densities under illumination and in the dark, respectively. A larger $P(\mathrm{E}, \mathrm{T})$ value indicates a more efficient charge dissociation in the PSCs. Fig. 9 shows a representative curve of $J_{\mathrm{ph}}$ versus effective voltage $\left(V_{\text {eff }}\right)$, where $V_{\text {eff }}=V_{\mathrm{o}}-V_{\mathrm{a}}$, $V_{\mathrm{o}}$ is the voltage at $J_{\mathrm{ph}}=0$ and $V_{\mathrm{a}}$ is the applied voltage. It is generally assumed that all the photogenerated excitons are dissociated into free charge carriers at high $V_{\text {eff }}$ and $J_{\text {sat }}$ will only depend on the maximum exciton generation rate $\left(G_{\max }\right)$ by $J_{\text {sat }}=q L G_{\max }$, where $q$ is the elementary charge and $L$ is the thickness of the active layer. A larger $G_{\max }$ indicates more excitons are generated in the active layer.

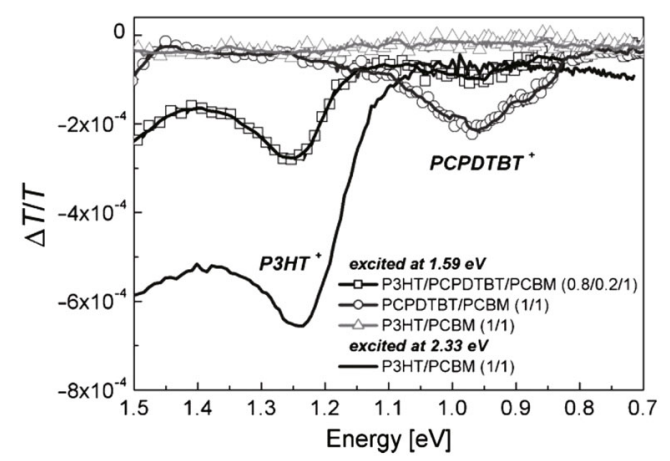

Figure 8 Photoinduced absorption spectra of the blended films. Reprinted with permission from Ref. [21]. Copyright 2010, WILEY-VCH.

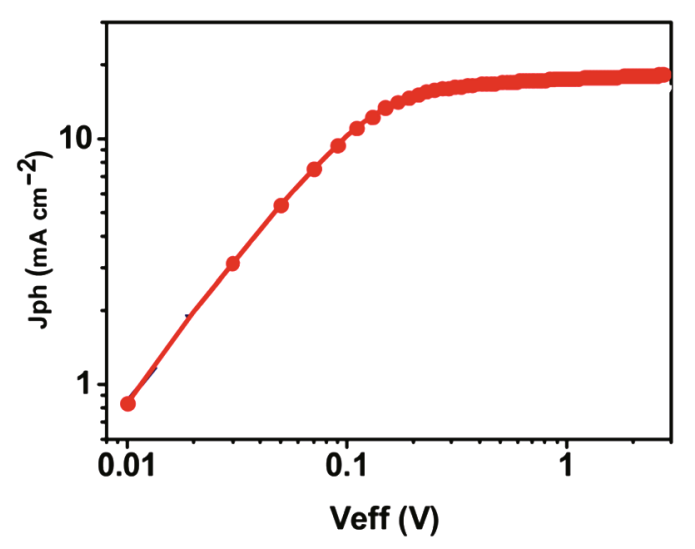

Figure 9 A representative curve of photocurrent density versus effective voltage curves.

\section{Charge transport and recombination}

The charge transport in the active layer is commonly characterized by the space charge limited current (SCLC) method based on the $J$ - $V$ curves. The charge mobility $(\mu)$ can be calculated by using Equation (2):

$$
J=\frac{9}{8} \varepsilon_{0} \varepsilon_{\mathrm{r}} \mu \frac{V^{2}}{L^{3}},
$$

where $\varepsilon_{0}$ is the vacuum permittivity, $\varepsilon_{\mathrm{r}}$ is the relative dielectric constant of the organic film, $V$ is the applied voltage, and $L$ is the active layer thickness. To measure the charge mobility by SCLC method, electron-only or holeonly devices have to be fabricated based on the active layer. Such devices usually have a different configuration with the original PSCs to avoid the injection of the opposite charge carriers. Nevertheless, the electric-field dependent 'charge carrier extraction in a linearly increasing voltage' (CELIV) characteristics of PSCs can determine the charge mobility in devices with the same configuration [23]. The charge carrier mobility of the organic film with moderate conductivity can be estimated based on Equation (3) $[54,55]$ :

$$
\mu=\frac{2 d^{2}}{3 A t_{\max }^{2}\left(1+0.36 \frac{\Delta j}{j_{0}}\right)},
$$

where $\mu$ is the mobility, $d$ is the thickness of the $\mathrm{BHJ}$ active layer, $t_{\max }$ is the time when the extracted current reaches its maximum value, $A$ is the slope of the extraction voltage ramp, $j_{0}$ is the dark capacitive current, and $\Delta j$ is the transient current peak height (see Fig. 10).

The changes in charge recombination kinetics after introducing the third component in PSCs can be measured 

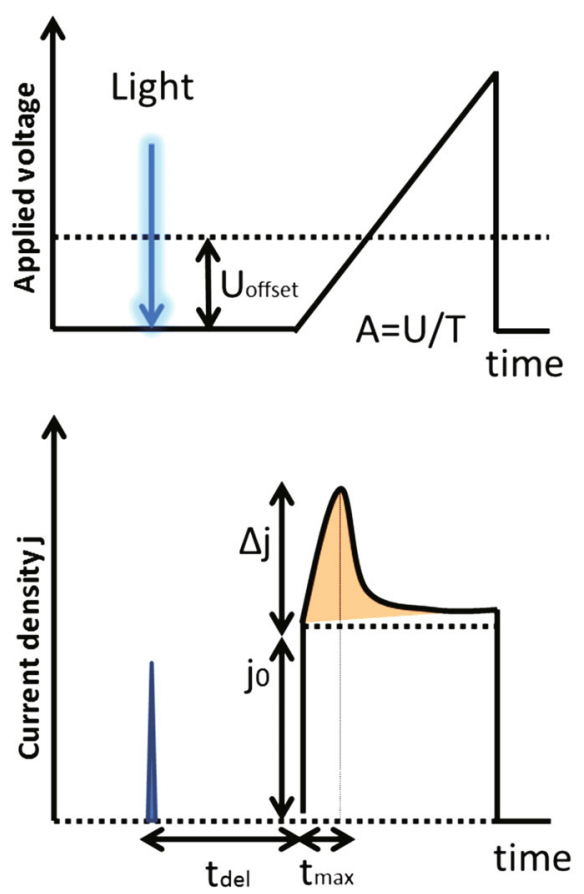

Figure 10 Schematic illustration and experimental setup of Photo-CELIV measurement. Reprinted with permission from Ref. [23]. Copyright 2014, Macmillan Publishers Limited.

by monitoring $J_{\mathrm{sc}}$ as a function of illumination intensity. Quantitatively, $J_{\text {sc }}$ follows a power-law dependence on light intensity $\left(J_{\text {sc }} \propto P_{\text {light }}^{S_{1}}\right)$. Weak bimolecular recombination in the device would result in a linear dependence of $J_{\mathrm{sc}}$ on light intensity with the $S$ value close to 1 , while sublinear scaling of photocurrent with $P_{\text {light }}$ indicates partial loss of charge carriers during the charge transport process due to bimolecular recombination [28].

Besides the relationship between $J_{s c}$ and $P_{\text {light }}$, the light intensity dependence of $V_{\text {oc }}$ provides direct insight into the role of trap-assisted recombination versus second-order recombination under open-circuit conditions [56,57]. In particular, the slope of $V_{\text {oc }} v s . \ln \left(P_{\text {light }}\right)$ should equal $k T / q$ in the case of second-order recombination. However, in the presence of additional trap-assisted recombination losses, a stronger dependency of $V_{\text {oc }}$ on the light intensity is typically observed. In this case, the slope of $V_{\text {oc }} v s$. $\ln \left(P_{\text {light }}\right)$ is closer to $2 k T / q$ [58-60]. So a smaller slope (close to 1) means the PSC does not suffer from trap-assisted bimolecular recombination.

In order to gain a deeper insight into the impact of the structural organization on the electronic properties of the ternary composite systems, transient photovoltage (TPV) measurements are usually employed to monitor recombination as a function of light intensity. In a TPV experiment, a device is photoexcited at open circuit with a short laser pulse and the resulting voltage transient decay is measured $[61,62]$. The rate at which the voltage relaxes towards equilibrium conditions can be then used as a measure of charge carrier life time. This can give useful information on charge carrier recombination kinetics [43].

To get more insight into the transport properties of the ternary blends, integrative mode time of flight ( $\mathrm{j}-\mathrm{ToF})$ measurements can be employed. This technique has been proven to give valuable information on the charge carrier dynamics in BHJ solar cells [63,64]. For example, Fig. 11a shows the j-ToF signals of the PCPDTBT:PCBM binary PSCs [21]. The saturation of the signal at time zero under high pump intensities indicates that charge carrier recombination is dominantly bimolecular. The absence of a plateau region in this curve (i.e., purely exponential decay of the extracted current) indicates that the recombination kinetics are of Langevin type [21]. In this case, the second
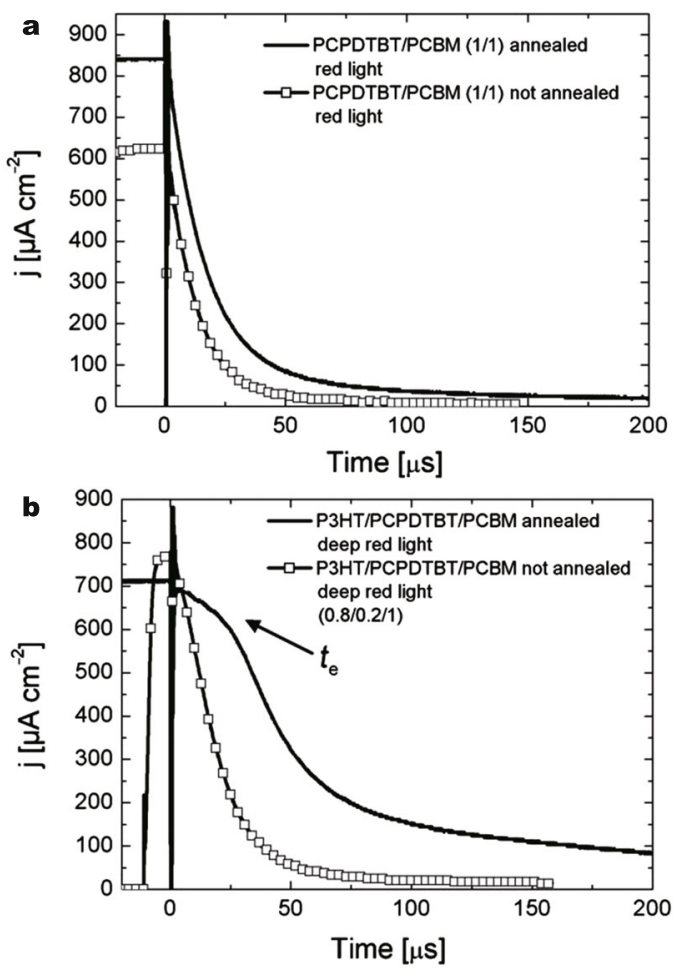

Figure 11 Integration mode time-of-flight ( $\mathrm{j}$-ToF) traces of non-annealed (full lines) and annealed (open squares) devices based on (a) PCPDTBT/PCBM and (b) P3HT/PCPDTBT/PCBM. Reprinted with permission from Ref. [21]. Copyright 2010, WILEY-VCH. 
order recombination constant $\beta_{\mathrm{L}}$ of $2 \times 10^{-10} \mathrm{~cm}^{3} \mathrm{~s}^{-1}$ is obtained by using Equation (4):

$$
\beta_{\mathrm{L}}=e \frac{\mu}{\varepsilon \varepsilon_{0}},
$$

where $\mu$ is the sum of the mobilities of the charge carriers, $e$ is the electronic charge, $\varepsilon$ is the relative permittivity, and $\varepsilon_{0}$ is the vacuum permittivity. Fig. $11 \mathrm{~b}$ shows that the bimolecular recombination kinetics of the non-annealed P3HT:PCPDTBT:PCBM ternary blend is of Langevin type. However, for the annealed ternary device, it shows a plateau which turns into an exponential decay at the charge extraction time $t_{\mathrm{e}}$. The presence of this plateau indicates nonLangevin bimolecular recombination kinetics, whose rate constant $\beta_{\mathrm{NL}}$ is obtained from $t_{\mathrm{e}}$ (as indicated in Fig. 11b) and the extracted charge $Q_{\mathrm{e}}$ using Equation (5) [65]:

$$
\frac{e d_{\mathrm{L}}}{\beta_{\mathrm{NL}} t_{\mathrm{e}}}=\int_{0}^{\infty} j_{\mathrm{e}} d t=\frac{Q_{\mathrm{e}}}{S}
$$

where $d_{\mathrm{L}}$ is the active layer thickness, $j_{\mathrm{e}}$ is the extraction current density, and $S$ is the electrode area. Thus, in the annealed ternary device $\beta_{\mathrm{NL}}$ is calculated to be $3 \times 10^{-13}$ $\mathrm{cm}^{3} \mathrm{~s}^{-1}$, which is similar as the value $\left(2 \times 10^{-13} \mathrm{~cm}^{3} \mathrm{~s}^{-1}\right)$ of annealed P3HT:PCBM binary PSC. Therefore, the j-ToF data indicate that hole transport in the ternary blends is dominantly supported by the P3HT phase.

\section{Morphology characterization}

Transmission electron microscopy (TEM) can be used to probe the morphology of the ternary blend. Sometimes, the introduction of the third component to the binary blends can induce the formation of fibrous features of polymers [28] or change the sizes of aggregates of small-molecular acceptors [26], which can be distinguished in the TEM images. In addition, X-ray scattering techniques are helpful to understand changes in molecular packing, structure ordering and domain sizes in the devices. So in most cases the morphology of the ternary blend film is determined by grazing incidence wide-angle $\mathrm{X}$-ray scattering (GIWAXS) and resonant soft X-ray scattering (RSoXS).

GIWAXS is a useful method to probe the molecular orientation and stacking in the active layer. By using this technique, whether face-on or edge-on orientation of the polymers exists in the film can be verified. Also, GIWAXS results can show that whether co-crystals are formed or not in the ternary blend film [40]. Besides the molecular ordering, another important morphological factor that will determine the photovoltaic performance is how these localized molecular crystals and aggregates form phase separated domains in the $\mathrm{BHJ}$ blend. RSoXS studies provide access to the spatial dimensions of phase-separated domains with statistical significance. For example, the RSoXS profile of the PTB7: $\mathrm{PC}_{71} \mathrm{BM}$ blend film shows a diffuse scattering at $q \approx 0.006 \AA^{-1}$, while that of the PID2:PC ${ }_{71} \mathrm{BM}$ blend film demonstrates a peak centered at a $q$ value of $\sim 0.003 \AA^{-1}$. Thus, according to Scherrer equation [66], the phase-separated domains in PID2: $\mathrm{PC}_{71} \mathrm{BM}$ blend film are larger than those in the PTB7:PC ${ }_{71} \mathrm{BM}$ film [14,41].

\section{FUTURE OUTLOOK OF TERNARY BLEND PSCs}

Using ternary architecture is a very effective strategy for overcoming the limitations of binary blend PSCs. Almost every aspect of binary PSCs could be improved in a ternary structure including light harvesting, exciton dissociation, charge transport, and morphology. These improvements can lead to simultaneously much enhanced PCE in many high-performance ternary systems. In addition, the potential of many wide-bandgap polymers with moderate performance could be re-evaluated in ternary blends. The simple structure ternary solar cells are much easier to fabricate than multilayer tandem cells, endowing their lower cost in potential applications.

However, challenges still exist in this research area. Gathering benefits from the different aspects mentioned above into one single system is still difficult. For instance, lowbandgap polymer donor with broad absorption and high hole mobility is ideal for the third component to extend the absorption spectrum, but it will decrease the $V_{\text {oc }}$ of ternary blend PSCs, simultaneously. Currently, the thickness of ternary active layers are commonly limited to the same as the corresponding binary system, so the incomplete light absorption in such thin films is still a problem in many ternary systems. Moreover, understanding clearly about the charge dynamics of ternary blend PSCs needs to be solved. Once these obstacles are overcome, the performance of ternary blend PSCs can be pushed to the next level. As a result, ternary solar cells provide a new avenue to develop high-performance OSCs with bright application prospects.

Received 12 May 2016; accepted 8 June 2016; published online 24 June 2016

1 Günes S, Neugebauer H, Sariciftci NS. Conjugated polymer-based organic solar cells. Chem Rev, 2007, 107: 1324-1338 
2 Thompson BC, Fréchet JMJ. Polymer-fullerene composite solar cells. Angew Chem Int Ed, 2008, 47: 58-77

3 Lin Y, Li Y, Zhan X. Small molecule semiconductors for high-efficiency organic photovoltaics. Chem Soc Rev, 2012, 41: 4245-4272

4 Yu G, Gao J, Hummelen JC, et al. Polymer photovoltaic cells: enhanced efficiencies via a network of internal donor-acceptor heterojunctions. Science, 1995, 270: 1789-1791

5 Tang CW. Two-layer organic photovoltaic cell. Appl Phys Lett, 1986, 48: 183

6 Zhao J, Li Y, Yang G, et al. Efficient organic solar cells processed from hydrocarbon solvents. Nat Energy, 2016, 1: 15027

7 Zhao W, Qian D, Zhang S, et al. Fullerene-free polymer solar cells with over $11 \%$ efficiency and excellent thermal stability. Adv Mater, 2016, 28: 4734-4739

8 Ameri T, Khoram P, Min J, et al. Organic ternary solar cells: a review. Adv Mater, 2013, 25: 4245-4266

9 Shockley W, Queisser HJ. Detailed balance limit of efficiency of p-n junction solar cells. J Appl Phys, 1961, 32: 510

$10 \mathrm{Li} \mathrm{W}$, Furlan A, Hendriks $\mathrm{KH}$, et al. Efficient tandem and triple-junction polymer solar cells. J Am Chem Soc, 2013, 135: 5529-5532

11 You J, Chen CC, Hong Z, et al. 10.2\% Power conversion efficiency polymer tandem solar cells consisting of two identical sub-cells. Adv Mater, 2013, 25: 3973-3978

12 You J, Dou L, Yoshimura K, et al. A polymer tandem solar cell with 10.6\% power conversion efficiency. Nat Commun, 2013, 4: 1446

13 Kang H, Kee S, Yu K, et al. Simplified tandem polymer solar cells with an ideal self-organized recombination layer. Adv Mater, 2015, 27: 1408-1413

14 Zhang J, Zhang Y, Fang J, et al. Conjugated polymer-small molecule alloy leads to high efficient ternary organic solar cells. J Am Chem Soc, 2015, 137: 8176-8183

15 An Q, Zhang F, Zhang J, et al. Versatile ternary organic solar cells: a critical review. Energy Environ Sci, 2016, 9: 281-322

16 Chen YC, Hsu CY, Lin RYY, et al. Materials for the active layer of organic photovoltaics: ternary solar cell approach. ChemSusChem, 2013, 6: 20-35

17 Khlyabich PP, Burkhart B, Rudenko AE, et al. Optimization and simplification of polymer-fullerene solar cells through polymer and active layer design. Polymer, 2013, 54: 5267-5298

18 Yang L, Yan L, You W. Organic solar cells beyond one pair of donor-acceptor: ternary blends and more. J Phys Chem Lett, 2013, 4: 1802-1810

19 Cheng P, Zhan X. Versatile third components for efficient and stable organic solar cells. Mater Horiz, 2015, 2: 462-485

20 Lu L, Kelly MA, You W, et al. Status and prospects for ternary organic photovoltaics. Nat Photon, 2015, 9: 491-500

21 Koppe M, Egelhaaf HJ, Dennler G, et al. Near IR sensitization of organic bulk heterojunction solar cells: towards optimization of the spectral response of organic solar cells. Adv Funct Mater, 2010, 20: 338-346

22 Yang L, Zhou H, Price SC, et al. Parallel-like bulk heterojunction polymer solar cells. J Am Chem Soc, 2012, 134: 5432-5435

23 Yang YM, Chen W, Dou L, et al. High-performance multiple-donor bulk heterojunction solar cells. Nat Photon, 2015, 9: 190-198

24 Derue L, Dautel O, Tournebize A, et al. Thermal stabilisation of polymer-fullerene bulk heterojunction morphology for efficient photovoltaic solar cells. Adv Mater, 2014, 26: 5831-5838

25 Liao MH, Tsai CE, Lai YY, et al. Morphological stabilization by supramolecular perfluorophenyl- $\mathrm{C}_{60}$ interactions leading to efficient and thermally stable organic photovoltaics. Adv Funct Mater, 2014, 24: 1418-1429
26 Campoy-Quiles M, Kanai Y, El-basaty A, et al. Ternary mixing: a simple method to tailor the morphology of organic solar cells. Org Electron, 2009, 10: 1120-1132

27 Zhang Y, Deng D, Lu K, et al. Synergistic effect of polymer and small molecules for high-performance ternary organic solar cells. Adv Mater, 2015, 27: 1071-1076

$28 \mathrm{Lu} \mathrm{L}, \mathrm{Xu} \mathrm{T}$, Chen W, et al. Ternary blend polymer solar cells with enhanced power conversion efficiency. Nat Photon, 2014, 8: 716-722

29 Faist MA, Shoaee S, Tuladhar S, et al. Understanding the reduced efficiencies of organic solar cells employing fullerene multiadducts as acceptors. Adv Energy Mater, 2013, 3: 744-752

30 Shao S, Zheng K, Pullerits T, et al. Enhanced performance of inverted polymer solar cells by using poly(ethylene oxide)-modified $\mathrm{ZnO}$ as an electron transport layer. ACS Appl Mater Interfaces, 2013, 5: 380-385

31 Cha H, Chung DS, Bae SY, et al. Complementary absorbing starshaped small molecules for the preparation of ternary cascade energy structures in organic photovoltaic cells. Adv Funct Mater, 2013, 23: 1556-1565

32 Kang H, Kim KH, Kang TE, et al. Effect of fullerene tris-adducts on the photovoltaic performance of P3HT:fullerene ternary blends. ACS Appl Mater Interfaces, 2013, 5: 4401-4408

33 Huang JH, Velusamy M, Ho KC, et al. A ternary cascade structure enhances the efficiency of polymer solar cells. J Mater Chem, 2010, 20: $2820-2825$

34 Hoppe H, Sariciftci NS. Polymer solar cells. In: Marder SR, Lee KS (eds.). Photoresponsive Polymers II. Heidelberg: Springer, 2008, $1-86$

35 Li Y, Zou Y. Conjugated polymer photovoltaic materials with broad absorption band and high charge carrier mobility. Adv Mater, 2008, 20: 2952-2958

36 Liu S, You P, Li J, et al. Enhanced efficiency of polymer solar cells by adding a high-mobility conjugated polymer. Energy Environ Sci, 2015, 8: 1463-1470

37 Chen H, Guo Y, Yu G, et al. Highly $\pi$-extended copolymers with diketopyrrolopyrrole moieties for high-performance field-effect transistors. Adv Mater, 2012, 24: 4618-4622

38 Li J, Zhao Y, Tan HS, et al. A stable solution-processed polymer semiconductor with record high-mobility for printed transistors. Sci Rep, 2012, 2: 754

$39 \mathrm{Lu} \mathrm{H}$, Zhang X, Li C, et al. Performance enhancement of polymer solar cells by using two polymer donors with complementary absorption spectra. Macromol Rapid Commun, 2015, 36: 1348-1353

40 Kouijzer S, Li W, Wienk MM, et al. Charge transfer state energy in ternary bulk-heterojunction polymer-fullerene solar cells. J Photon Energy, 2015, 5: 057203

41 Lu L, Chen W, Xu T, et al. High-performance ternary blend polymer solar cells involving both energy transfer and hole relay processes. Nat Commun, 2015, 6: 7327

42 Liu T, Huo L, Sun X, et al. Ternary organic solar cells based on two highly efficient polymer donors with enhanced power conversion efficiency. Adv Energy Mater, 2016, 6: 1502109

43 Kan Z, Colella L, Canesi EV, et al. Charge transport control via polymer polymorph modulation in ternary organic photovoltaic composites. J Mater Chem A, 2016, 4: 1195-1201

44 Xiao L, Gao K, Zhang Y, et al. A complementary absorption small molecule for efficient ternary organic solar cells. J Mater Chem A, 2016, 4: 5288-5293

45 Benten H, Nishida T, Mori D, et al. High-performance ternary blend all-polymer solar cells with complementary absorption bands from visible to near-infrared wavelengths. Energy Environ 
Sci, 2016, 9: 135-140

46 Ko SJ, Lee W, Choi $\mathrm{H}$, et al. Improved performance in polymer solar cells using mixed $\mathrm{PC}_{61} \mathrm{BM} / \mathrm{PC}_{71} \mathrm{BM}$ acceptors. Adv Energy Mater, 2015, 5: 1401687

47 Cheng P, Li Y, Zhan X. Efficient ternary blend polymer solar cells with indene- $\mathrm{C}_{60}$ bisadduct as an electron-cascade acceptor. Energy Environ Sci, 2014, 7: 2005-2011

48 Shi H, Fu W, Shi M, et al. A solution-processable bipolar diketopyrrolopyrrole molecule used as both electron donor and acceptor for efficient organic solar cells. J Mater Chem A, 2015, 3: 1902-1905

49 Liu W, Shi H, Fu W, et al. Efficient ternary blend polymer solar cells with a bipolar diketopyrrolopyrrole small molecule as cascade material. Org Electron, 2015, 25: 219-224

50 Vandewal K, Tvingstedt K, Gadisa A, et al. Relating the open-circuit voltage to interface molecular properties of donor:acceptor bulk heterojunction solar cells. Phys Rev B, 2010, 81: 125204

51 Graham KR, Erwin P, Nordlund D, et al. Re-evaluating the role of sterics and electronic coupling in determining the open-circuit voltage of organic solar cells. Adv Mater, 2013, 25: 6076-6082

52 Graham KR, Cabanetos C, Jahnke JP, et al. Importance of the donor:fullerene intermolecular arrangement for high-efficiency organic photovoltaics. J Am Chem Soc, 2014, 136: 9608-9618

53 Blom PWM, Mihailetchi VD, Koster LJA, et al. Device physics of polymer:fullerene bulk heterojunction solar cells. Adv Mater, 2007, 19: 1551-1566

54 Mozer AJ, Sariciftci NS, Lutsen L, et al. Charge transport and recombination in bulk heterojunction solar cells studied by the photoinduced charge extraction in linearly increasing voltage technique. Appl Phys Lett, 2005, 86: 112104

55 Ito $\mathrm{S}$, Chen $\mathrm{P}$, Comte $\mathrm{P}$, et al. Fabrication of screen-printing pastes from $\mathrm{TiO}_{2}$ powders for dye-sensitised solar cells. Prog PhotovoltRes Appl, 2007, 15: 603-612

56 Gilot J, Barbu I, Wienk MM, et al. The use of $\mathrm{ZnO}$ as optical spacer in polymer solar cells: theoretical and experimental study. Appl Phys Lett, 2007, 91: 113520

57 Leong WL, Cowan SR, Heeger AJ. Differential resistance analysis of charge carrier losses in organic bulk heterojunction solar cells: observing the transition from bimolecular to trap-assisted recombination and quantifying the order of recombination. Adv Energy Mater, 2011, 1: 517-522
Tuladhar SM, Poplavskyy D, Choulis SA, et al. Ambipolar charge transport in films of methanofullerene and poly(phenylenevinylene)/methanofullerene blends. Adv Funct Mater, 2005, 15: $1171-1182$

59 Gasparini N, Salvador M, Fladischer S, et al. An alternative strategy to adjust the recombination mechanism of organic photovoltaics by implementing ternary compounds. Adv Energy Mater, 2015, 5: 1501527

60 Koster LJA, Mihailetchi VD, Ramaker R, et al. Light intensity dependence of open-circuit voltage of polymer:fullerene solar cells. Appl Phys Lett, 2005, 86: 123509

61 Shuttle CG, O'regan B, Ballantyne AM, et al. Experimental determination of the rate law for charge carrier decay in a polythiophene: Fullerene solar cell. Appl Phys Lett, 2008, 92: 093311

62 Hamilton R, Shuttle CG, O'regan B, et al. Recombination in annealed and nonannealed polythiophene/fullerene solar cells: transient photovoltage studies versus numerical modeling. J Phys Chem Lett, 2010, 1: 1432-1436

63 Street RA, Schoendorf M, Roy A, et al. Interface state recombination in organic solar cells. Phys Rev B, 2010, 81: 205307

64 Juška G, Viliunas M, Arlauskas K, et al. Space-charge-limited photocurrent transients: the influence of bimolecular recombination. Phys Rev B, 1995, 51: 16668

65 Pivrikas A, Juška G, Österbacka $\mathrm{R}$, et al. Langevin recombination and space-charge-perturbed current transients in regiorandom poly(3-hexylthiophene). Phys Rev B, 2005, 71: 125205

66 Smilgies DM. Scherrer grain-size analysis adapted to grazing-incidence scattering with area detectors. J Appl Crystallogr, 2009, 42: $1030-1034$

Acknowledgments This work was supported by the National Natural Science Foundation of China (91233205, 21161160443, 21534003 and 51273020), Program for Changjiang Scholars and Innovative Research Team in University and the Fundamental Research Funds for the Central Universities.

Author contributions $\quad \mathrm{Bo} \mathrm{Z}$ and $\mathrm{Xu} \mathrm{X}$ designed the outlines; $\mathrm{Lu} \mathrm{H}$ and $\mathrm{Xu} \mathrm{X}$ searched the reference papers. All the authors participated in writing the paper.

Conflict of interest The authors declare that they have no conflict of interest. 

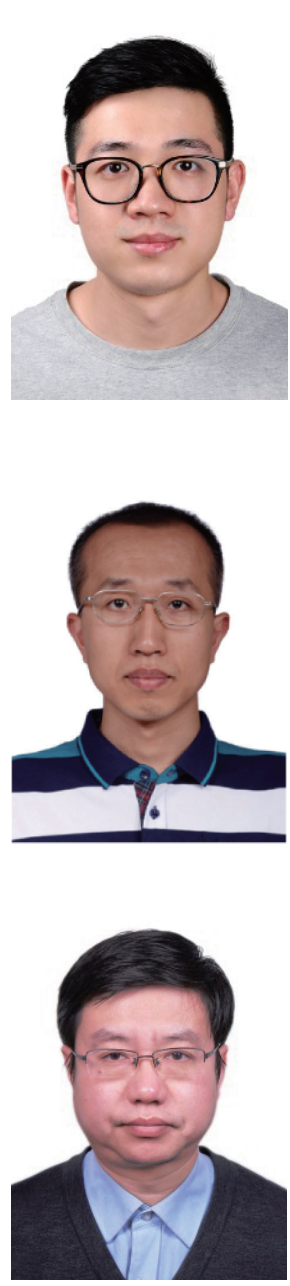

Heng Lu received his MSc degree in polymer chemistry and physics from Beijing Normal University in 2015. Now he is a $\mathrm{PhD}$ student under the supervision of Prof. Zhishan Bo. His research interests are focused on ternary blend organic solar cells and tandem organic solar cells.
Xinjun Xu received his $\mathrm{PhD}$ degree in chemistry from the Institute of Chemistry, Chinese Academy of Sciences (ICCAS) in 2007. Then he joined to the University of Science and Technology Beijing and was promoted to the position of associate professor in 2008. In 2016, he moved to the College of Chemistry, Beijing Normal University. Currently, his research focuses on the organic photovoltaic and photoconductive devices.
Zhishan Bo received his PhD degree from the Department of Chemistry, Jilin University in 1997. After 5 years' postdoctoral study in Germany and the USA, he joined the ICCAS as a professor supported by the "Hundred Talents Program of CAS" in 2002. In 2010, he moved to the College of Chemistry, Beijing Normal University. His research interests include organic electronics, polymer light emitting materials, dye sensitized photovoltaic cells, polymer-based bulk heterojunction solar cells, perovskite solar cells, and polymer synthesis.

\section{有机光伏的新趋势: 三元共混聚合物太阳能电池}

陆恒, 徐新军 ${ }^{*}$, 薄志山 ${ }^{*}$

摘要 过去几年, 三元共混聚合物太阳能电池作为一种新型的共混结构电池, 由于其优秀的潜质受到国内外研究学者的广泛关注. 相较于 传统的二元共混聚合物太阳能电池, 这种三元共混结构能有效地提高太阳能电池的各项参数, 从而使电池的光电转换效率有了大幅度的提 升. 本综述主要总结了制备高效率三元共混太阳能电池的设计思路并介绍了这一领域的最新进展, 讨论了三元共混聚合物太阳能电池中 第三组分的主要作用和表征方法. 